\title{
A Comparative Evaluation of an Automated Functional Assay for Von Willebrand Factor Activity in Type I Von Willebrand Disease
}

\author{
Shiue-Wei Lai ${ }^{1-3}$ \\ Chia-Yau Chang ${ }^{3,4}$ \\ Shin-Nan Cheng 1,5,6 \\ Shu-Hsia Hu' \\ Chung-Yu Lai ${ }^{7}$ \\ Yeu-Chin Chen ${ }^{1,2}$ \\ 'Hemophilia Care and Research Center, \\ Tri-Service General Hospital, Taipei, \\ Taiwan; ${ }^{2}$ Division of Hematology/ \\ Oncology, Department of Internal \\ Medicine, Tri-service General Hospital, \\ National Defense Medical Center, Taipei, \\ Taiwan; ${ }^{3}$ School of Medicine, Graduate \\ Institute of Clinical Medicine, Taipei Medical \\ University, Taipei, Taiwan; ${ }^{4}$ Division of \\ Pediatric Hematology/Oncology, \\ Hemophilia Center, Taipei Medical \\ University Hospital, Taipei, Taiwan; \\ ${ }^{5}$ Department of Pediatrics, Tungs' Taichung \\ MetroHarbor Hospital, Taichung, Taiwan; \\ ${ }^{6}$ Department of Pediatrics, National \\ Defense Medical Center, Taipei, Taiwan; \\ ${ }^{7}$ Graduate Institute of Aerospace and \\ Undersea Medicine, National Defense \\ Medical Center, Taipei City, II4, Taiwan
}

Background: von Willebrand factor ristocetin cofactor activity (VWF:RCo) is the standard functional assay used for von Willebrand disease (VWD) diagnosis. However, it has some drawbacks including being time consuming and labor intensive and having high interlaboratory variability. The HemosIL VWF activity assay has the advantages of both high speed and automation. The purpose of this study was to prospectively compare these two functional assays for type 1 VWD detection.

Methods: Plasma samples from 108 subjects were assessed in this study. HemosIL VWF activity was measured with the HemosIL latex immunoturbidimetric commercial kits by the ACL TOP coagulation analyzer. VWF:RCo was measured by platelet aggregation method. Pearson correlation analyses were performed to estimate the correlation of HemosIL VWF activity with VWF:RCo. Receiver-operator characteristic (ROC) curve analysis was used to evaluate the performance of the two diagnostic tests.

Results: The correlation coefficient between VWF:RCo and HemosIL VWF activity was 0.874 overall and was 0.761 and 0.811 in the cohorts of type 1 VWD and non-VWD, respectively. The sensitivity and specificity of HemosIL VWF activity assay for type 1 VWD identification were $94.7 \%$ and $80.0 \%$, respectively, and the ROC curve of HemosIL VWF activity was larger than that of VWF:RCo ( 0.928 vs $0.863, \mathrm{p}=0.0138)$. Finally, the positive and negative predictive values of the HemosIL VWF activity assay for type 1 VWD detection were $72.0 \%$ and $96.6 \%$, respectively.

Conclusion: Our results demonstrate that the HemosIL VWF activity assay was an effective method for type 1 VWD screening and diagnosis. It carried good sensitivity and specificity and had a higher ROC curve than VWF:RCo besides showing good correlation with VWF: RCo. With its advantages of greater speed and automated performance, these results suggest that the HemosIL VWF activity assay was reliable and precise in the clinical setting.

Keywords: von Willebrand factor antigen, von Willebrand disease, VWF ristocetin cofactor activity, VWF:RCo, HemosIL VWF activity

\section{Introduction}

von Willebrand disease (VWD) is the most common inherited bleeding disorder with a prevalence of $1-2 \%$ of the general population..$^{1-3}$ but it is less recognized in South and East Asian countries. ${ }^{4,5}$ It is caused by a quantitative or qualitative defect of von Willebrand factor (VWF). VWF plays a vital role in normal hemostasis not only by mediating platelet adhesion to injured endothelium but also by binding and protecting coagulation factor VIII (FVIII) from degradation. ${ }^{6-8}$ Symptoms associated with VWD
Correspondence: Yeu-Chin Chen
Division of Hematology/Oncology, Department of Internal Medicine, Tri-Service General Hospital, Nationa Defense Medical Center, No. 325,

Section 2, Chenggong Road, Neihu,

Taipei, I I4, Taiwan

Tel +886-2-87927208

Fax +888-2-87927209

Email yeuchin99@gmail.com 
typically present with easy bruising, epistaxis, excessive postoperative or posttraumatic bleeding, gum bleeding, and menorrhagia. ${ }^{1}$

The diagnosis of VWD is based on correlation of clinical findings with multiple laboratory tests results and family studies, including bleeding-assessment tools, prothrombin time (PT), activated partial thromboplastin time (aPTT), platelet functional analyzer-100 (PFA-100) closure times, FVIII, concentration of VWF antigen (VWF: $\mathrm{Ag}$ ), VWF-ristocetin cofactor activity (VWF:RCo), VWF collagen-binding activity (VWF:CB), FVIII-VWF binding activity, ristocetin induced platelet agglutination (RIPA) and VWF multimers analysis. ${ }^{9-12}$

There are three major types of VWD and quantitative defects include type 1 VWD, with partial deficiency of VWF, and type 3 VWD, with virtually complete deficiency of VWF. Type 2 VWD is caused by dysfunctional VWF and the qualitative variants comprise defects in multimerization (type 2A), spontaneous platelet binding (type 2B), defects in ligand binding with intact multimers (type 2M) and defects in factor VIII binding (type $2 \mathrm{~N}$ ). ${ }^{13}$

Type 1 VWD is most prevalent and accounts for $65-$ $80 \%$ of VWD cases, which may be heterozygous for the defective gene, leading to a partial deficiency of VWF in plasma and/or platelets with simultaneously reduced VWF activity and antigen. ${ }^{13,14}$ The patients usually present with mild to moderate mucosal bleeding symptoms, typically associated with a family history of bleeding and a quantitative reduction in VWF.,15 While this may seem relatively straight forward, it can sometimes be difficult to make a diagnosis, requiring correlation of clinical clues, family studies and interpretation of multiple laboratory tests results. Laboratory testing is often complicated by the fact that VWF is an acute phase reactant and can increase with stress, injury, surgery, pregnancy, and oral contraceptive use. In addition, no single laboratory test can definitively confirm the diagnosis of type 1 VWD and there is a lack of reliable screening tests complicating early diagnosis. Generally, when VWF:Ag level is below $30 \mathrm{IU} \mathrm{dL}^{-1}$ and VWF:RCo/VWF:Ag ratio larger than 0.7, type 1 VWD is diagnosed typically. ${ }^{12}$ Levels of between 30 and $50 \mathrm{IU} \mathrm{dL}^{-1}$ in a patient with a positive bleeding history may also indicate type 1 VWD. ${ }^{12}$

Among the various diagnostic tools, the VWF:RCo assay has been an indispensable criteria for the diagnosis of type 1 VWD. It is based on the property of the antibiotic ristocetin to agglutinate exogenous formalin-fixed platelets in the presence of VWF. ${ }^{16}$ Therefore, it can reproduce the ability of VWF to interact with one of its platelet receptors, the glycoprotein $\mathrm{Ib}-\mathrm{IX}-\mathrm{V}$ complex, in vitro. ${ }^{4}$ When sufficient ristocetin $(>1 \mathrm{mg} / \mathrm{mL})$ is added to a suspension of washed platelets and patient's platelet poor plasma, the extent and rate of platelet agglutination depend on the concentration of $\mathrm{VWF}^{3}$ Because the functional assay is the most common test of VWF activity, VWF: RCo assay combined with VWF:Ag are traditionally considered the first step in the diagnosis of VWD. ${ }^{3}$ However, besides being time consuming and labor-intensive, additional disadvantages of the VWF:RCo assay include variation in test results due to the technical experience of laboratory personnel and the requirement of fixed or fresh platelet concentrates. ${ }^{17,18}$

In recent years, several fully automated VWF:RCo assay protocols have been described. ${ }^{19-23}$ Higher throughput of samples with improved analytical precision compared with manual and semi-automated assays were observed. The HemosIL VWF activity assay (Instrumentation Laboratory, Kentucky, USA) is one such method. It is a latex particle-enhanced immunoturbidimetric assay designed for use on Instrumentation Laboratory analyzers for the diagnosis and classification of VWD. ${ }^{23}$ The reagent contains latex particles coated with a monoclonal anti-VWF antibody directed against the platelet-binding site on VWF (glycoprotein Ib receptor). The activity of VWF is determined by measuring the increase in turbidity produced by the agglutination of the latex reagent. It has been designed for use on Instrumentation Laboratory's coagulation analyzer. This assay has the advantages of short turnaround time and automated performance. $^{22,23}$ In this prospective study, we aimed to compare the HemosIL VWF activity assay with the conventional VWF:RCo method for type 1 VWD identification.

\section{Materials and Methods}

\section{Patients}

We prospectively studied archived plasma samples of 108 subjects, of which there were 28 patients diagnosed with type 1 VWD in our previously published cohort. ${ }^{24}$ Among the 108 subjects, 48 samples for which coagulation laboratory tests had been performed due to suspected VWD between January and December 2009 were also assessed. Thirty-eight of these 48 subjects were eventually ruled out as having VWD based on the VWF panel results including VWF:Ag, VWF:RCo, FVIII 
clotting activity assay and PFA-100 while 10 were diagnosed to have type 1 VWD. Finally, 32 healthy volunteers without symptoms of mucocutaneous bleeding, history of thrombocytopenia and no intake of anti-platelet agents and non-steroid anti-inflammatory drug within one week before blood tests were recruited as a normal control group. Subjects' blood types were also determined because VWF levels are lower in individuals with blood type O compared with non-O blood types. ${ }^{25}$ This study was approved by the ethics review board in our institution.

\section{Methods}

Nine parts of freshly drawn venous blood were collected into one part of $3.2 \%$ trisodium citrate from all the subjects. Platelet poor plasma (PPP) was obtained by centrifugation at $2360 \times \mathrm{g}$ for 10 minutes twice. Plasma from patients was collected in the same way as plasma from the volunteers. The PPP samples were stored at $-80^{\circ} \mathrm{C}$ and thawed at $37^{\circ} \mathrm{C}$ for at least 15 minutes. After thawing, the assays were performed within 2 hours. $^{26}$ Each patient's or subject's VWF activity assays including VWF ristocetin cofactor activity and HemosIL VWF activity were run at the same day.

\section{Von Willebrand Factor Antigen}

On the ACL TOP analyzer (IL, Kentucky, USA), VWF:Ag was measured with the HemosIL VWF latex-enhanced, turbidimetric immunoassay. The addition of $90 \mu \mathrm{L}$ of latex reagent and $70 \mu \mathrm{L}$ of buffer into $20 \mu \mathrm{L}$ of patient's plasma was operated by the ACL TOP. The agglutination was measured at $405 \mathrm{~nm}$ as a decrease in light transmittance.

\section{Von Willebrand Factor Activity}

The reference method was the ristocetin cofactor assay which was performed on a Chrono-log aggregometer model 560 (Chrono-log Corporation, Havertown, USA) using platelet concentrate (Taipei Blood Bank Centre, TBSF, Taipei, Taiwan) and ristocetin (Chrono-log Corporation, Havertown, USA). A 3-point reference curve was prepared with each run. Patient plasma was diluted 1:2 and 1:4, and both dilutions were assayed as described in National Committee for Clinical Laboratory Standards document H51-A. This assay is also based on automatic optical platelet aggregation. The plasma or its dilution $(50 \mu \mathrm{L})$ were added to $450 \mu \mathrm{L}$ of PPP (final platelet concentration: $200-300 \times 10^{9} / \mathrm{L}$ ) and incubated in the cuvette of the aggregation at $37^{\circ} \mathrm{C}$ with constant stirring for 5 minutes.
The HemosIL VWF activity assay was performed on the ACL TOP instrument. Patient plasma was prediluted 1 part plasma plus 2 parts diluent by the ACL TOP. The ACL TOP then added $150 \mu \mathrm{L}$ of latex reagent into $30 \mu \mathrm{L}$ of plasma, and agglutination was measured at $405 \mathrm{~nm}$ as a decrease in light transmittance. Calibration was done with the ACL TOP instrument.

\section{Criteria for VWD Diagnosis}

In this study, VWD was established if the patient had documented clinical evidence of mucocutaneous bleeding such as nasal bleeding or menorrhagia and had at least one of the following abnormal laboratory test results: ${ }^{12,27,28}$

(1) both low VWF:Ag $\left(<50 \mathrm{IU} \mathrm{dL}^{-1}\right)$ and VWF:RCo $(<$ $\left.50 \mathrm{IU} \mathrm{dL}^{-1}\right)$, (2) both low VWF:RCo and low FVIII:C ( $<50 \mathrm{IU}$ $\mathrm{dL}^{-1}$ ), (3) low VWF:RCo determined on at least two occasions, (4) either low VWF:Ag or VWF:RCo plus either prolonged bleeding time or both prolongation of PFA-100 with collagen-epinephrine and collagen-ADP closure times. Type 1 VWD is diagnosed with the VWF:RCo/VWF:Ag ratio larger than 0.7 and no defect of VWF multimers electrophoresis.

\section{Density Plot Analysis}

Density plot analysis was performed with the Gaussian kernel to evaluate the distribution of measured VWF activity with VWF:RCo and HemosIL VWF activity. This analysis was performed and visualized using "seaborn" package in Python, version 3.7.1.

\section{Statistical Analysis}

All analyses were performed using SPSS, version 26.0, software for Windows (SPSS, Inc.) and MedCalc Software, version 19.1.3. The significance level was 5\% for all analyses. Pearson's correlation analyses were used to estimate the correlation of VWF:RCo and HemosIL VWF activity. Paired $t$ tests were constructed to compare results between methods. Area under Receiver-operator characteristic (ROC) curve was used for evaluating the accuracy of the two diagnostic assays. The sensitivity and specificity as well as the positive and negative predictive values of the two functional assays were calculated and analyzed by nonparametric test.

\section{Ethics Approval and Consent to Participate}

This study has been approved by the appropriate ethics committee of Tri-Service General Hospital (approval 
number 2-098-05-067) and performed according to the ethical standards laid down in the 1964 Declaration of Helsinki and its later amendments. Informed consent was obtained from all individual participants included in the study.

\section{Results}

A total of 38 type 1 VWD patients and 70 non-VWD patients were recruited. The mean age of type 1 VWD patients was $35.4 \pm 15.2$ years which was older than the non-VWD subjects $(29.3 \pm 11.5$ years, $\mathrm{p}=0.033)$ (Table 1$)$. The gender distribution was also similar between the two groups ( $\mathrm{p}=0.749$ ), with male patients accounting for more than $70 \%$ of the study subjects. For VWF activity, the values measured with VWF:RCo and HemosIL VWF activity assays were both significantly lower in the type 1 VWD patients than in the non-VWD individuals (both $\mathrm{p}<0.001)$. The values of VWF:RCo/VWF:Ag and HemosIL VWF/VWF:Ag were both over 0.7, which was consistent with the diagnostic threshold for type 1 VWD. In the absence of dysfunctional VWF, there was no significant difference between type 1 VWD and non-VWD patients in terms of VWF:RCo/VWF:Ag and HemosIL VWF/VWF:Ag ( $\mathrm{p}=0.747$ and 0.536). Furthermore, the correlation coefficient between VWF:RCo and HemosIL VWF activity was 0.874 for all subjects (Figure 1A), suggesting good comparability between these two assays. However, the correlations were slightly lower for patients with type 1 VWD and without VWD, which were 0.761 and 0.811 , respectively (Figure $1 \mathrm{~B}$ and $\mathrm{C}$ ). On inspection of the correlation plot, the linearity was lost at higher values. The coefficient was determined mostly by samples with HemosIL VWF activity less than $150 \mathrm{IU} \mathrm{dL}^{-1}$ (regression fit: $y=1.135 x-5.332$ ). The mean value of activity was 63.88 for HemosIL VWF, about $4.2 \%$ lower than VWF:RCo. The loss of linearity could be explained by the density plot which showed substantial deviation of probability density near $100 \mathrm{IU} \mathrm{dL}^{-1}$ (Figure 2A). When dividing the subjects into VWD patients and healthy subjects, we found that this deviation was mostly contributed by the HemosIL VWF activity in healthy subjects rather than VWD patients (Figure 2B and C). Moreover, the two peaks seen in the density plot for HemosIL VWF activity suggested a discriminating ability for VWD diagnosis.

The area under the curve for the HemosIL VWF activity assay was significantly larger than that of VWF:RCo (0.928 versus $0.863, p=0.0138$ ) (Figure 3 ). There was same diagnostic sensitivity (94.7\%) of both assays for a normal cut-off value of $50 \mathrm{IU} \mathrm{dL}^{-1}$ for VWF activity. Although the specificity, PPV, NPV and accuracy were higher in the HemosIL VWF activity assay than those in VWF:RCo, which were 80.0, 72.0, 96.6\% and 85.1\%, respectively (Table 2), no statistical significance was achieved.

\section{Discussion}

VWF:RCo activity has been the mainstay of functional testing for type 1 VWD. However, it is associated with high variation among different techniques and across different laboratories (coefficient of variation [C.V.] is $25 \%$ or greater). ${ }^{29}$ The procedures of determining the VWF: RCo activity are also laborious and skill-demanding. Therefore, many clinical laboratories prefer outsourcing the VWF:RCo assays to institutions that are able to meet these requirements. Moreover, the traditional method involves platelet aggregation and ristocetin-induced platelet agglutination, which are not a physiologically natural process, ${ }^{30}$ even though enhanced the read-out of platelet aggregation has been introduced to improve the performance of VWF:RCo measurement. ${ }^{31}$ The other major problems with VWF:RCo testing are its poor sensitivity due to high limits of detection (LOD), with the lowest

Table I Comparison of Laboratory Results for the 108 Patient Samples

\begin{tabular}{|l|c|c|c|}
\hline Variables & Type I VWD (n=38) & Non-VWD (n=70) & p value \\
\hline Age (years) & $35.4 \pm 15.2$ & $29.3 \pm 11.5$ & 0.033 \\
Sex (\%) & & & 0.749 \\
Male & $29(76.3 \%)$ & $50(71.4 \%)$ & \\
Female & $9(23.7 \%)$ & $20(28.6 \%)$ & $<0.001$ \\
VWF:RCo (IU dL & \\
VWF:RCo/VWF:Ag & $24.9 \pm 14.8$ & $85.5 \pm 49.5$ & 0.747 \\
HemosIL VWF (IU dL & $0.82 \pm 0.27$ & $0.82 \pm 0.38$ & $<0.001$ \\
HemosIL VWF/VWF:Ag & $25.7 \pm 15.0$ & $80.5 \pm 33.2$ & 0.536 \\
\hline
\end{tabular}

Abbreviations: VWD, von Willebrand disease; VWF:RCo, von Willebrand factor ristocetin cofactor activity; HemosIL VWF, von Willebrand factor activity with ACL TOP. 

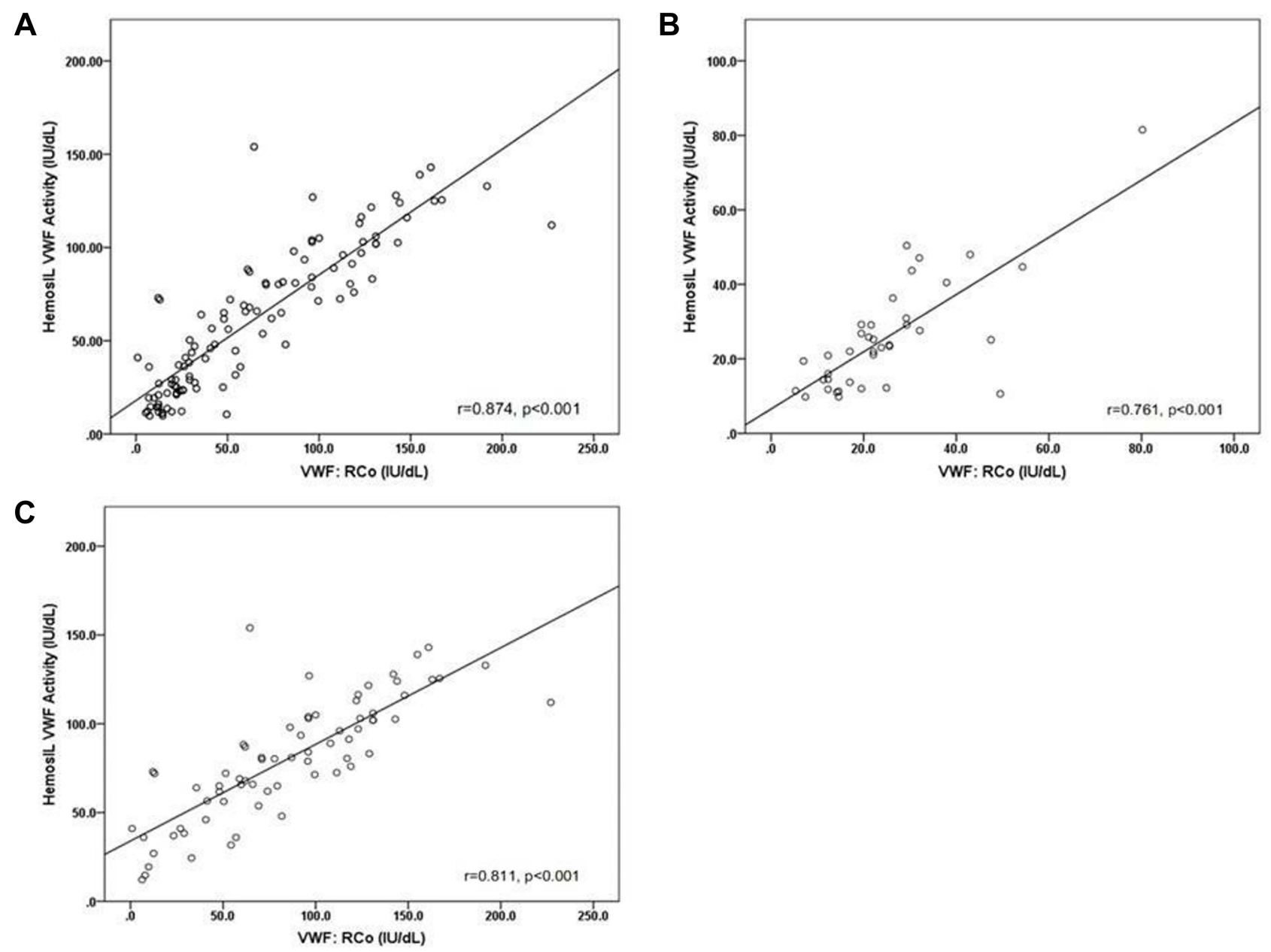

Figure I Linear regression by Scatter plot comparing the aggregation method for von Willebrand ristocetin cofactor activity (VWF:RCo) with the HemosIL VWF Activity Assay. (A) regression line: $y=0.673 x+18.021 \quad(n=108)$ in non-selective group (B) regression line: $y=0.768 x+6.527(n=38)$ in type I VWD group (C) regression line: $y=0.544$ $\mathrm{x}+34.00(\mathrm{n}=70)$ in non-VWD group. The $\mathrm{R}$ of model is $0.874,0.761$ and 0.811 respectively.

detectable VWF being around $10-15 \mathrm{IU} \mathrm{dL}^{-1}$ or even up to $20 \mathrm{IU} \mathrm{dL}{ }^{-1}$ and poor reproducibility. ${ }^{17,29}$ Although the VWF activity from automated HemosIL tend to be more reproducible than those performed on aggregometers, they may not perform equally well in terms of LOD. ${ }^{32}$

By definition, diagnosis of type 1 VWD requires a VWF:RCo and/or a VWF:Ag of less than 30 IU $\mathrm{dL}^{-1},{ }^{17}$ However, it is important to note that these criteria are based on expert opinion rather than high level of evidence. Historically, the diagnostic criteria for type 1 VWD is less stringent, requiring only a VWF value less than $50 \mathrm{IU} \mathrm{dL}^{-1}$ for either VWF: Ag or VWF:RCo. Furthermore, because the plasma concentration of VWF is a continuous variable, ${ }^{33}$ the distinction between low VWF and type 1 VWD is loosely defined, making determination of desmopressin prescription or other replacement therapy difficult.
Therefore, the diagnostic criteria by Sadler et al were adopted to avoid compromise in patient care. ${ }^{34}$

ACL TOP is a fully automated coagulation analyzer, designed for simultaneous measurement of routine and special coagulation parameters. ${ }^{32}$ It utilizes fresh and lyophilized plasma samples, and has an intra-assay and interassay C.V. below 5\% for most of the parameters both in the normal and in the pathological ranges. ${ }^{35}$ In this study, we evaluated the performance of the testing system consisting of HemosIL reagents and the ACL TOP analyzer. The cut-off value was defined as $50 \mathrm{IU} \mathrm{dL}^{-1}$ for $\mathrm{VWF}$ activity to screen for type 1 VWD. The performance of HemosIL VWF activity assay demonstrated good sensitivity of $94.7 \%$ and acceptable specificity of $80.0 \%$. Our study used prospective design to assess the clinical feasibility of the HemosIL VWF activity assay and compared it to the VWF:RCo activity assay. We demonstrated that the 
A

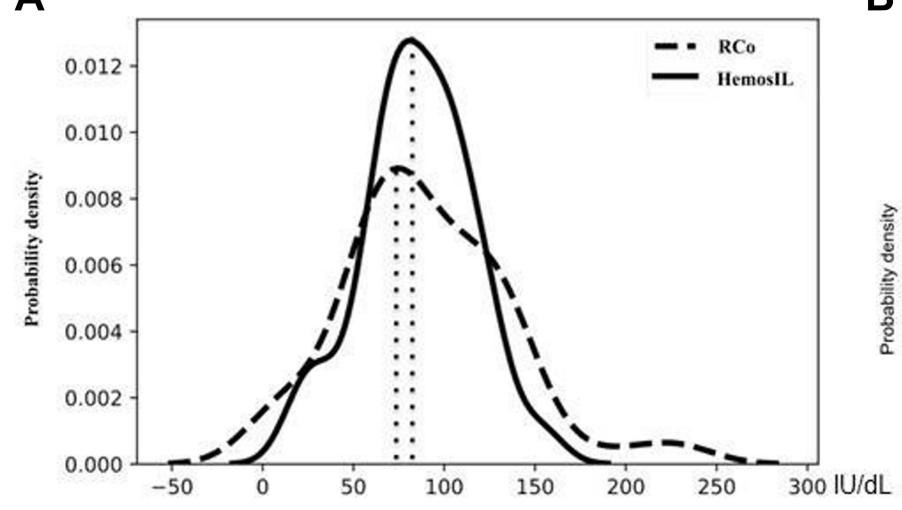

B

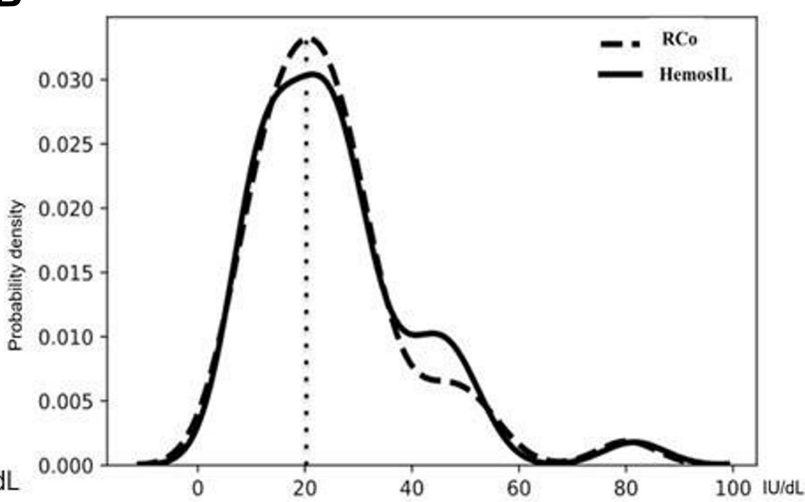

C

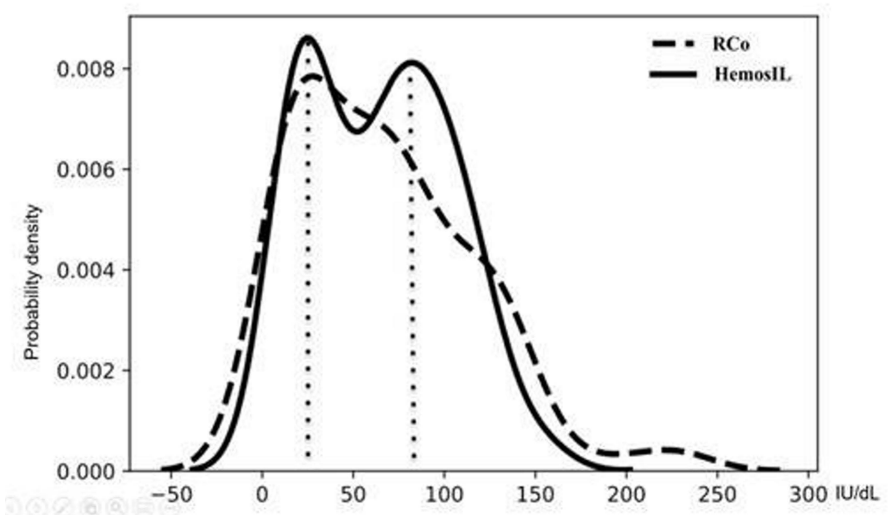

Figure 2 Density plots of VWF activity for VWF:RCo and the HemosIL VWF Activity Assay in (A) Healthy subjects, (B) Type I VWD subjects, and (C) Combined healthy and type I VWD subjects.

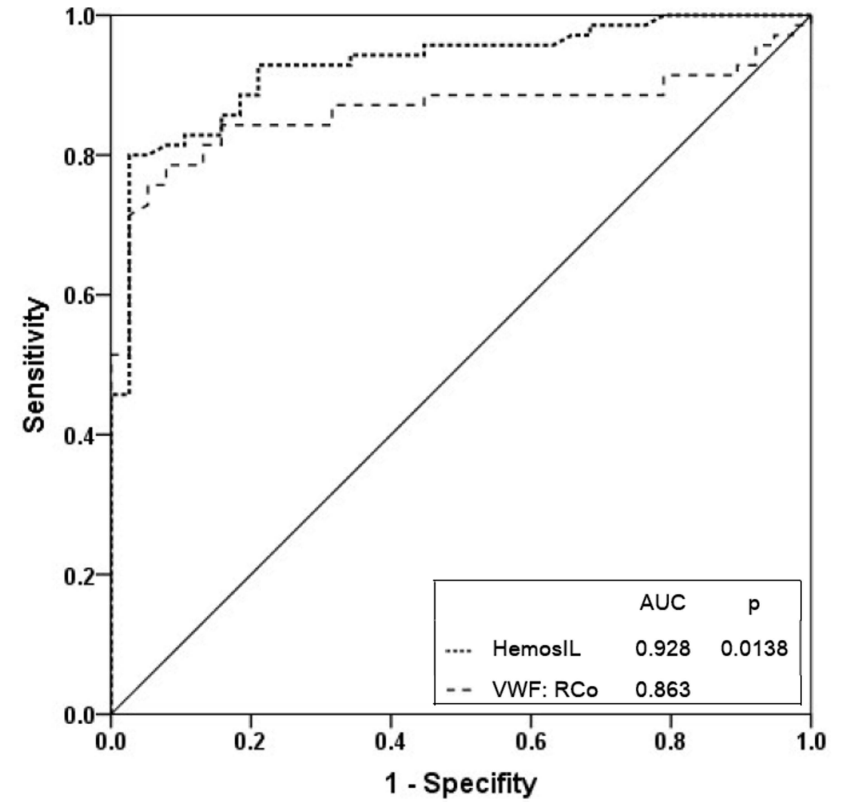

Figure 3 Receiver-operator curve (ROC) analyses of VWF:RCo and the HemosIL VWF Activity Assay. The HemosIL VWF Activity Assay has a significant higher area under ROC than the method of VWF:RCo $(p=0.0138)$.
HemosIL VWF activity assay had good correlation with conventional VWF:RCo activity assay both in type 1 VWD patients as well as non-VWD subjects. Additionally, the diagnostic performance was better for the HemosIL VWF activity assay, characterized by higher area under the curve, specificity, PPV, NPV and accuracy.

Based on a review of literatures, the platelet agglutination method (VWF ristocetin cofactor activity assay) demonstrated inferior values in terms of correlation C.V., intra-assay C.V., inter-assay C.V. and LOD. ${ }^{17,36-38}$ The performance between the ELISA and immunoturbidimetric assays were similar with regard to the values of correlation coefficient, inter-assay C.V. and the LOD values. $^{36-39}$ The flow cytometry assay included fewer numbers of patient samples and did not perform as well as ELISA assays based on the results of correlation coefficient. ${ }^{39}$ Our study method was based on immunoturbidimetry. We recruited type 1 VWD patients and demonstrated the highest sensitivity, suggesting feasibility of this 
Table 2 Performance Metrics for the HemosIL VWF Activity with a Cut-off Value of $50 \%$

\begin{tabular}{|l|c|c|c|c|c|}
\hline Variables & Sensitivity (\%) & Specificity (\%) & PPV (\%) & NPV (\%) & Accuracy (\%) \\
\hline VWF:RCo & $36 / 38(94.7)$ & $53 / 70(75.7)$ & $36 / 53(67.9)$ & $53 / 55(96.3)$ & $89 / 108(82.4)$ \\
HemoslL VWF & $36 / 38(94.7)$ & $56 / 70(80.0)$ & $36 / 50(72.0)$ & $56 / 58(96.6)$ & $92 / 108(85.1)$ \\
\hline
\end{tabular}

Abbreviations: PPV, positive predict value; NPV, negative predict value; VWF:RCo, von Willebrand factor ristocetin cofactor activity; HemosIL VWF, von Willebrand factor activity with $A C L$ TOP.

assay as a screening method for this subtype. In addition, we evaluated the screening methods for type 1 VWD using ROC analyses.

Limitations of the automated detection method using HemosIL VWF activity, include a lower sensitivity and higher inaccuracy at lower levels, underestimation of activities and variable results depending on the type of analyzer and reagent lots used. ${ }^{23,39,40}$ In addition, due to our study design with use of 28 archived specimens from the known type 1 VWD patients in our previously reported cohort, bias may exist on the basis of double blindness. Finally, we presented our results based on diagnostic criteria for type 1 VWD that employed a cut-off value of $50 \mathrm{IU} \mathrm{dL} \mathrm{d}^{-1}$ for VWF activity and used the ROC curve to confirm the performance of HemosIL VWF activity $(p=0.0138)$. Higher specificity $(92.9 \%)$ but lower sensitivity (76.3\%) was observed (data not shown) when using a cut-off value of $30 \%$ for VWF activity which was not considered suitable for a screening tool.

In conclusion, the automatic HemosIL VWF activity by the ACL TOP analyzer was highly correlated with the traditional VWF:RCo assay using washed platelets. It was sensitive for assaying VWF activity and could be useful for rapid screening of type 1 VWD with the advantage of less labor due to full automation, high turn-around time and cost savings. Taken together, we believe the results of our analyses provide valuable practical guidance to clinicians who care for this population. Further studies with larger numbers of patients with type 1 VWD are warranted to validate these findings.

\section{Acknowledgments}

The authors would like to thank Dr. Vivek R. Sharma, Research Scientist and Medical Director, at the Adult Hemophilia Program, Division of Medical oncology/ Hematology, University of Louisville, School of Medicine, for his critical review of this manuscript. We would further like to thank the research assistant, Ms. Ya-Fang Yang for her skillful performance of laboratory assays and the study nurses for their hard work and diligence in compiling patients' blood samples and study records.

\section{Funding}

This work was supported by the Tri-Service General Hospital Research Funds TSGH-C98-038.

\section{Disclosure}

The authors report no conflicts of interest in this work.

\section{References}

1. Rodeghiero F, Castaman G, Dini E. Epidemiological investigation of the prevalence of von Willebrand's disease. Blood. 1987;69 (2):454-459.

2. Werner EJ, Broxson EH, Tucker EL, Giroux DS, Shults J, Abshire TC. Prevalence of von Willebrand disease in children: a multiethnic study. J Pediatr. 1993;123(6):893-898.

3. Bowman M, Hopman WM, Rapson D, Lillicrap D, James P. The prevalence of symptomatic von Willebrand disease in primary care practice. J Thromb Haemost. 2010;8(1):213-216.

4. Sadler JE, Mannucci PM, Berntorp E, et al. Impact, diagnosis and treatment of von Willebrand disease. Thromb Haemost. 2000;84 (2):160-174.

5. Srivastava A, Rodeghiero F. Epidemiology of von Willebrand disease in developing countries. Semin Thromb Hemost. 2005;31(5):569-576.

6. Foster PA, Fulcher CA, Marti T, Titani K, Zimmerman TS. A major factor VIII binding domain resides within the amino-terminal 272 amino acid residues of von Willebrand factor. J Biol Chem. 1987;262 (18):8443-8446.

7. Kulkarni S, Dopheide SM, Yap CL, et al. A revised model of platelet aggregation. J Clin Invest. 2000;105(6):783-791.

8. Doggett TA, Girdhar G, Lawshe A, et al. Selectin-like kinetics and biomechanics promote rapid platelet adhesion in flow: the GPIb(alpha)-vWF tether bond. Biophys $J$. 2002;83(1):194-205.

9. Leebeek FW, Eikenboom JC. Von Willebrand's Disease. $N$ Engl $J$ Med. 2016;375(21):2067-2080.

10. Rodeghiero F, Tosetto A, Abshire T, et al. ISTH/SSC bleeding assessment tool: a standardized questionnaire and a proposal for a new bleeding score for inherited bleeding disorders. J Thromb Haemost. 2010;8(9):2063-2065.

11. Elbatarny M, Mollah S, Grabell J, et al. Normal range of bleeding scores for the ISTH-BAT: adult and pediatric data from the merging project. Haemophilia. 2014;20(6):831-835.

12. James PD, Connell NT, Ameer B, et al. ASH ISTH NHF WFH 2021 guidelines on the diagnosis of von Willebrand disease. Blood $A d v$. 2021;5(1):280-300.

13. Sadler JE, Budde U, Eikenboom JC, et al. Update on the pathophysiology and classification of von Willebrand disease: a report of the Subcommittee on von Willebrand Factor. J Thromb Haemost. 2006;4 (10):2103-2114.

14. Robertson J, Lillicrap D, James PD. Von Willebrand disease. Pediatr Clin North Am. 2008;55(2):377-392, viii-ix.

15. Flood VH, Christopherson PA, Gill JC, et al. Clinical and laboratory variability in a cohort of patients diagnosed with type $1 \mathrm{VWD}$ in the United States. Blood. 2016;127(20):2481-2488. 
16. Macfarlane DE, Stibbe J, Kirby EP, Zucker MB, Grant RA, McPherson J. Letter: a method for assaying von Willebrand factor (ristocetin cofactor). Thromb Diath Haemorrh. 1975;34(1):306-308.

17. Nichols WL, Hultin MB, James AH, et al. von Willebrand disease (VWD): evidence-based diagnosis and management guidelines, the National Heart, Lung, and Blood Institute (NHLBI) expert panel report (USA). Haemophilia. 2008;14(2):171-232.

18. Mori F, Rossi P, Nardini I, Gambelli D, Farina C. Evaluation of von Willebrand factor activity in factor VIII/von Willebrand factor concentrates with the automated von Willebrand factor: activity IL test. Blood Coagul Fibrinolysis. 2010;21(3):221-228.

19. Lattuada A, Preda L, Sacchi E, Gallo L, Federici AB, Rossi E. A rapid assay for ristocetin cofactor activity using an automated coagulometer (ACL 9000). Blood Coagul Fibrinolysis. 2004;15 (6):505-511.

20. Redaelli R, Corno AR, Borroni L, et al. von Willebrand factor ristocetin cofactor (VWF:RCo) assay: implementation on an automated coagulometer (ACL). J Thromb Haemost. 2005;3 (12):2684-2688.

21. Strandberg K, Lethagen S, Andersson K, Carlson M, Hillarp A. Evaluation of a rapid automated assay for analysis of von Willebrand ristocetin cofactor activity. Clin Appl Thromb Hemost. 2006;12(1):61-67.

22. Salem RO, Van Cott EM. A new automated screening assay for the diagnosis of von Willebrand disease. Am J Clin Pathol. 2007;127 (5):730-735

23. Pinol M, Sales M, Costa M, Tosetto A, Canciani MT, Federici AB. Evaluation of a new turbidimetric assay for von Willebrand factor activity useful in the general screening of von Willebrand disease. Haematologica. 2007;92(5):712-713.

24. Chen YC, Yang L, Cheng SN, Hu SH, Chao TY. von Willebrand disease: a clinical and laboratory study of sixty-five patients. Ann Hematol. 2011;90(10):1183-1190.

25. Gill JC, Endres-Brooks J, Bauer PJ, Marks WJ Jr, Montgomery RR. The effect of $\mathrm{ABO}$ blood group on the diagnosis of von Willebrand disease. Blood. 1987;69(6):1691-1695.

26. Olson JD, Brockway WJ, Fass DN, Magnuson MA, Bowie EJ. Evaluation of ristocetin-Willebrand factor assay and ristocetin-induced platelet aggregation. Am J Clin Pathol. 1975;63 (2):210-218.

27. Federici AB, Castaman G, Mannucci PM. Italian association of Hemophilia C. Guidelines for the diagnosis and management of von Willebrand disease in Italy. Haemophilia. 2002;8(5):607-621.

28. Federici AB. Clinical diagnosis of von Willebrand disease. Haemophilia. 2004;10(Suppl 4):169-176.
29. Kitchen S, Jennings I, Woods TA, Kitchen DP, Walker ID, Preston FE. Laboratory tests for measurement of von Willebrand factor show poor agreement among different centers: results from the United Kingdom National External Quality Assessment Scheme for Blood Coagulation. Semin Thromb Hemost. 2006;32(5):492-498.

30. Preston FE. Laboratory diagnosis of hereditary bleeding disorders: external quality assessment. Haemophilia. 1998;4(Suppl 2):12-18.

31. Patzke J, Schneppenheim R. Laboratory diagnosis of von Willebrand disease. Hamostaseologie. 2010;30(4):203-206.

32. Milos M, Herak D, Kuric L, Horvat I, Zadro R. Evaluation and performance characteristics of the coagulation system: ACL TOP analyzer - HemosIL reagents. Int J Lab Hematol. 2009;31(1):26-35.

33. Sadler JE. Low von Willebrand factor: sometimes a risk factor and sometimes a disease. Hematology Am Soc Hematol Educ Program. 2009;106-112. doi:10.1182/asheducation-2009.1.106

34. Sadler JE. A revised classification of von Willebrand disease. For the subcommittee on von Willebrand factor of the Scientific and Standardization Committee of the International Society on Thrombosis and Haemostasis. Thromb Haemost. 1994;71 (4):520-525.

35. Appert-Flory A, Fischer F, Jambou D, Toulon P. Evaluation and performance characteristics of the automated coagulation analyzer ACL TOP. Thromb Res. 2007;120(5):733-743.

36. Lawrie AS, Mackie IJ, Machin SJ, Peyvandi F. Evaluation of an automated platelet-based assay of ristocetin cofactor activity. Haemophilia. 2011;17(2):252-256.

37. Vinayagam S, Simons LR, Chowdary P, Thurlow P, Brooks SV, Riddell AF. Evaluation of a rapid von Willebrand factor activity latex immuno assay for monitoring of patients with von Willebrand disease (VWD) receiving DDAVP or VWF replacement therapy. Haemophilia. 2014;20(4):e304-310.

38. Chen D, Daigh CA, Hendricksen JI, et al. A highly-sensitive plasma von Willebrand factor ristocetin cofactor (VWF:RCo) activity assay by flow cytometry. J Thromb Haemost. 2008;6(2):323-330.

39. De Vleeschauwer A, Devreese K. Comparison of a new automated von Willebrand factor activity assay with an aggregation von Willebrand ristocetin cofactor activity assay for the diagnosis of von Willebrand disease. Blood Coagul Fibrinolysis. 2006;17 (5):353-358.

40. Hillarp A, Stadler M, Haderer C, Weinberger J, Kessler CM, Romisch J. Improved performance characteristics of the von Willebrand factor ristocetin cofactor activity assay using a novel automated assay protocol. J Thromb Haemost. 2010;8 (10):2216-2223.
International Journal of General Medicine

\section{Publish your work in this journal}

The International Journal of General Medicine is an international, peer-reviewed open-access journal that focuses on general and internal medicine, pathogenesis, epidemiology, diagnosis, monitoring and treatment protocols. The journal is characterized by the rapid reporting of reviews, original research and clinical studies across all disease areas. The manuscript management system is completely online and includes a very quick and fair peer-review system, which is all easy to use. Visit http://www.dovepress.com/ testimonials.php to read real quotes from published authors. 